\title{
Chinese Morpheme and Syntax Based Negative Transfer in High School Students' English Writing
}

\author{
Xiyan $\mathrm{Hu}^{1, \dagger}$ Wenyi $\mathrm{Lu}^{2, \dagger}$ Yiting Wang ${ }^{3, *},{ }^{*}$ Qinglin Zhang ${ }^{4, \dagger}$ \\ ${ }^{1}$ Nanjing Foreign Language School, Nanjing, Jiangsu, China \\ ${ }^{2}$ Aidi School, Beijing, China \\ ${ }^{3}$ Northwest Agriculture and Forestry University, Xi'an, Shaanxi, China \\ ${ }^{4}$ Guangxi University of Foreign Languages, Nanning, Guangxi Zhuang Autonomous Region, China \\ *Corresponding author. Email: rcelestine@my.ccri.edu \\ These authors contributed equally.
}

\begin{abstract}
In the context of an increasing focus on international communication, most students in China choose English as their second language. However, their English learning will be affected by their mother tongue in terms of the language transfer theory. On this basis, learners of a second language will inevitably be influenced by the thinking pattern of mother tongue, errors frequently occur in the Second Language Acquisition called negative transfer. This paper aims to investigate the impact of negative transfer about Morpheme and Syntax on Chinese high school students' English writing by collecting 80 English essays from 24 Chinese high school students. Specifically, we divide the errors found into 5 categories: Errors in Determiner, Errors in Tense, Errors in Subject-predicate agreement, Errors in the plural form of Noun, and Errors in the complementizer of Clause, to analyse the impact of the negative transfer. According to those primary data, there is an interference in high school students' writing. Besides, the numbers of errors in the plural form of Noun and Tense reflections are relatively higher than others, which are attributed to the morpho-syntactic differences between Chinese and English. Our results also indicate that the reason for the existence of different errors can hopefully help learners to understand the way to address such a problem in the future. These results shed light for the reduction of errors in students' English writing with the emphasis of the morpho-syntactic differences between languages.
\end{abstract}

Keywords: Negative Transfer, the Second Language Acquisition, Morpheme, Syntax.

\section{INTRODUCTION}

With globalization and modernization, nearly a third of the world's population speak fluent or basic English, which even continues to grow [1]. English, as an international language, has been selected by UNESCO as one of the official language. Contemporarily, English has become the lingua franca of more than 50 countries and regions, and has become the second language of choice in almost every country [2]. Meanwhile, English is now the most important language in international science and technology, economic pillar, financial trade, political and diplomatic consultation, culture and entertainment industry [1]. Therefore, English has become an important language tool for cross-cultural communication, which has attracted much attention.

As a second language, English is acquired by learners, and the mother tongue plays an important role which can not be ignored. It is bound to affect the formation of English communication patterns and discourse, which is called "Language transfer", i.e., the transfer of the acquired knowledge from the first language environment to the second language learning process [3]. The study of native speakers transfer is of great significance and promotion to Second Language Acquisition [4]. The positive effect from L1 is called the positive transfer while the negative one is called the negative transfer [5]. Negative language transfer is a common problem in SLA [6].

The negative transfer of native speakers is reflected in many aspects of foreign language learning [7], e.g., phonetic transfer, morphological and syntactic transfer, pragmatic transfer, and so on [5]. Among them, English writing is greatly affected by negative transfer. Among the four basic skills of listening, speaking, reading and writing in English learning, writing is the most difficult part that scholars used to measure language proficiency [8], since the learner must continuously search for 
vocabularies to accurately express their feelings in a proper way. While listening and reading both are receiving skills, users should recognize words and contents and quickly translate them into their mother tongue without making major mistakes. Writing and speaking, as productive skills, further require the users to create their own content and convey them to others without making mistake [9], which are more likely to be affected by a person's mother tongue. Furthermore, writing is more difficult than speaking because of the different levels of sophistication they required. As speaking requires the user to be able to communicate with others effectively and fast, these two characters largely lower the level of vocabularies and grammar people used while speaking. Writing, especially free writing, has almost no time limit and low immediacy [10]. Therefore, human beings are expected to increase their language complexity on writing to compensate the extra time they cost, i.e., is common to see someone who is good at speaking but not at writing.

Negative transfer in Chinese is reflected in writing mainly in Chinese morpheme and syntax, specifically in Determiner, Tense, Subject-predicate agreement, the plural forms of Noun, and the complementizer of Clause. In English grammar rules, it is the expression of a certain degree of meaning through morphological changes to verbs [11]. Subject-predicate agreement means that the subject and the predicate need to be unified in terms of "number", e.g., the predicate form of flowers should be are instead of is, while in Chinese there is no such rule [12]. The plural of a noun usually requires 's' or 'es' at the end of the word, but the plural of a noun in Chinese does not have this morphological change, and its plural meaning is realized mainly by combining it with other syntactic components [13]. With regard to the coronary, there is no such concept in Chinese. A measure word appears before a noun in Chinese, but in daily life the measure word is usually omitted, which does not affect the meaning. In contrast, English is a morphology-heavy language, and the absence of a coronary is not recognized [14]. As a result, students' written expressions often ignore the and plural forms of nouns, the change of person and number of verbs, and the confusion of tenses is common. This negative transfer usually leads Chinese students to unconsciously bring Chinese thinking into English in the process of learning English, which has a negative impact on English learning.

The number of Chinese people who speak English as a second language is not the minority. Some scholars have collated relevant data and found that among 415.95 million Chinese foreign-language learners, 390.16 million had learned English [15]. While high school students are now at a critical stage in the transition between primary English learning in the primary school and advanced English learning in the university, some Chinese high school students also take studying abroad into account, which also urges them to use the second language coherently and correctly [16]. However, when Chinese high school students are acquiring English, the negative transfer in Morpheme and Syntax will occur [17, 18]. As a result, Chinese high school students' English writing is worth discussing.

Based on the analysis above, this article aims to figure out how mother tongue (Chinese) influences the High School learners' English writing about morpheme and syntax. In this case, we have conducted analysis on samples collected from high school students, and discuss results of the survey in the following 5 carriers of errors: Determiner, Tense, Subject-predicate agreement, the plural forms Noun, and the complementizer of Clause (conjunction)

\section{METHODOLOGY}

In order to analyze how Chinese Morpheme and Syntax based Negative Transfer influences high school students' English writing, we collected 80 essays (38 written by males and 42 written by females) from 24 Chinese high school students (12 males and 12 females), who plan to study in English speaking countries or choose English as their major for universities in China.

\section{RESULTS AND DISCUSSIONS}

\section{Errors in Samples}

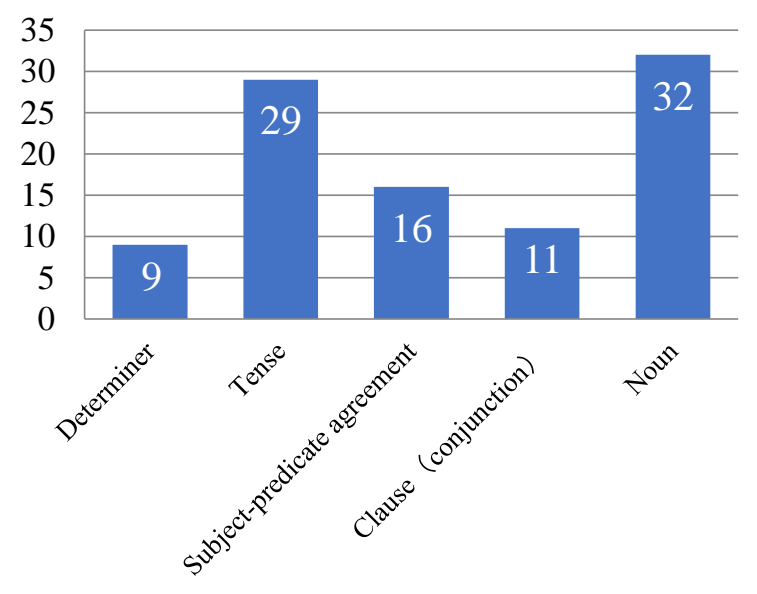

Figure 1 Error in Samples 


\section{Portions of different errors}

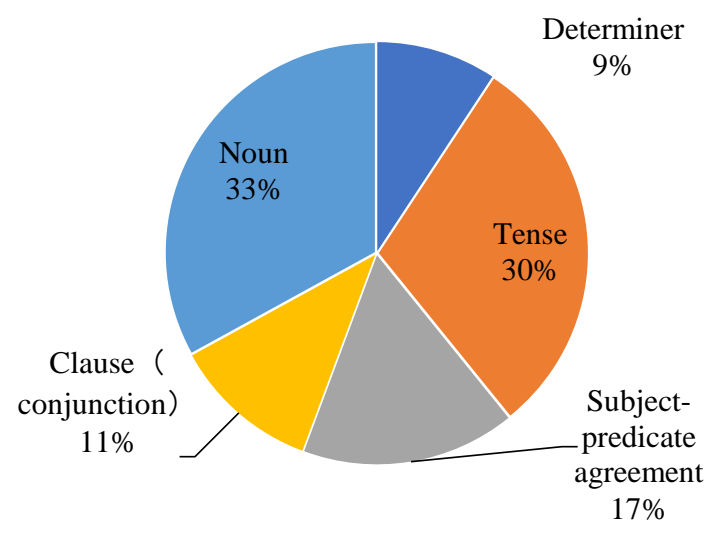

Figure 2 Portions of different types of errors

As shown in Figure 1, in the 80 compositions, we found 97 errors in Morpheme and Syntax in total, which were briefly divided those errors into 5 categories: 9 in Determiner, 29 in Tense, 16 in Subject-predicate agreement, 11 in Clause, and 32 in Noun. Figure 2 displays the portions of the different types of errors: Determiner take up $9 \%$ of all the errors, Tense takes up $30 \%$, Subject-predicate agreement takes up $17 \%$, Clause takes up $11 \%$, and Noun takes up $33 \%$. Subsequently, we will illustrate how negative transfer from Chinese causes these different types of errors.

\subsection{Errors in Determiners}

Determiners refer to a small set of words in English used with nouns to limit or give definiteness to the application. In English, a determiner must be added prior to a noun when referring to it, which is common for people to make mistakes during the process, especially when using articles: 'a', 'an' and 'the'. Among the three articles, 'an' and 'a' are indefinite and seem easier to grasp for learners after a period of training. Nevertheless, the usage of the definite article 'the' is significantly harder and many of the high school students tend to overuse. All the determiner-related mistakes they made happened when using 'the' ( 9 of 9), below is a sentence written in one of the samples:

a) The great increase of the tuition makes the students spend most of their money paying the tuition.

Here the author used four 'the', two in front of 'tuition', one before 'great' and the other before 'students'. This is apparently an overuse: the purpose is probably to make readers understand the students and tuition mentioned are for college instead of anything else. However, the writer ignored a fact that what he or she was trying to establish is a general situation, not a specific case, hence it has become unnecessary to add the definite article [19, 20].
The reason for such an overuse is probably because the range of determiners is different and does not contain articles in mandarin Chinese [21]. In addition, a noun can stand alone to represent itself without an article in front, i.e., it's unnecessary to distinguish different kinds of articles. Furthermore, it's easy to use 'a/an' because all people need to do is adding one before the countable nouns that first appear in a sentence, but there are more rules related to 'the' so people tend to make mistakes, a clear evidence of negative transfer.

\subsection{Errors in Tense}

Tense is a form of the English predicate that indicates the Time. In English, there are three types of temporal reflection: present, past, and future. As a result, with various types of aspect, and the predicate has different forms of composition in different tenses [22]. The variation in the form is frequently mentioned by teachers, but the errors still take place [23]. Out of the 97 errors, the number of errors in Tense is the second greatest, which almost takes $30 \%$ of the total number. This indicates that Chinese high school students often confuse or omit verb conjugations in different tenses when writing in English, especially when they use the past tense.

Here are some examples (the students are talking about the same story):

b)... Since the excitement has mounted as I reached the last one...

c)... The excitement mounts as I reached the last one...

d)...Excitement mount as I get the question right...

All students narrate the story of their own, they all notice that they should use past tense, and they indeed use the past tense when they describe the action taken by the people. However, they ignore that the tense should be consistent and they use the present tense (one perfect, one indefinite, another omits the suffix) to describe the time when "the excitement mounted". Although the first sentence (b) seems to use the perfect aspect to emphasize the sequence of the action, it actually uses the present tense (has) instead of the past tense (had).

This indicates that the negative transfer in the tense from Chinese. Though the students have realized that they should use the past tense when describing what has already taken place, they still forget to change the predicate into the right form. The reason is that the difference between Chinese and English also lies in the composition of the tenses [24]. Chinese predicates do not have a change of tense, and Time in Chinese is often expressed by such Chinese auxiliaries as “通常 (usually)”, “即将 (soon)”, “已 经 (already)”, tec. However, it is also suggested by the samples that when 
the Chinese use the auxiliary " $?$ " to indicate the past tense, which plays a similar role as the suffix "-ed". In this case, the student will less likely to omit the change in the predicate in past tense. In contrast, when there is no change in the verb in the Chinese, the students will use the wrong tense because of the negative transfer.

\subsection{Errors in Subject-predicate agreement}

Among the syntactic rules of English, subjectpredicate agreement is the most basic one. Subjectpredicate agreement refers to the need to agree with each other in terms of "person" and "number", while there is no such rule in Chinese [25]. The difference between English and Chinese has a negative impact on English learners' understanding and mastery of this English syntactic rule, which is the negative transfer phenomenon that Chinese students face in English learning. The third highest error rate of subject-verb agreement was found in the statistics of the causes of errors in high school students' writing.

For example, the following subject-verb agreement errors were found in the collected essays.

e) The audience realize the growing rate in the tuition fee is faster and faster, which constrain their after-college life. (False)

f) The audience realize the growing rate in the tuition fee is faster and faster, which constrains their aftercollege life. (True)

g) Spending too much on fancy devices increase the burden of colleges. (False)

h) Spending too much on fancy devices increases the burden of colleges. (True)

In the above two cases, students ignore the rule that in English grammar rule, subordinate clause or verbal noun as subject requires the predicate verb to be singly three. Since the predicate verb itself does not change form in the sentence in Chinese. In fact, there is no agreement on the "number" between the subject and the predicate, which causes Chinese high school students to make this type of mistake in their writing.

\subsection{Errors in the Plural Form of Noun}

Based on the analysis of the 80 essays collected, the number of noun singular and plural errors was the highest (32) in high school students' English writing. This type of error accounted for $33 \%$ of all error types.

Nouns play an important role in all languages. Noun is a kind of word class, which is a uniform name for person, thing, place, or abstract concept. Every human language has the concept of "number", and the use of nouns in different languages may vary [26]. In English, nouns have the division of countable nouns and non- countable nouns, while countable nouns can be divided into singular nouns and plural nouns. Plural nouns are obtained through the tortuous changes of singular nouns, that is, the concept of plural nouns is accomplished by changing nouns by Inflectional affixes, whereas, in Chinese, the number of nouns is generally reflected by “ 们" or measuring words. Besides, there is no concept of twisting and turning nouns or words to reflect the number of nouns. English belongs to the Indo-European language department, is the phonetic text, from comprehensive to analytical language development of the language, while Chinese belongs to the Han-Tibetan language system which is the Ideograph, analytical language [27]. There are great differences in language and type between the two. Therefore, in English writing, the use of noun singular plural error is common. This phenomenon because of the difference between the two languages affects the acquisition of second language learners to the second language, reflecting the impact of negative language transfer.

According to corpus data analysis, common noun singular plural and errors can be divided into two categories. The first is grammatical errors. The English countless singular nouns through the twists and turns into noun plurals of the law is not consistent, it has irregular changes (e.g., tooth-teeth, deer-deer, sheep-sheep, person-people). There are generally three types of errors, i.e., singular instead of plural, plural instead of singular, and plural variation confusion. Mistakes occur in writing when students are not proficient in these grammar rules. The second is the wrong understanding of the meaning, some nouns in the form of singular and plural not only in grammar, but also in meaning \{e.g. property(assets)-properties(character), water(potable water)-waters(water area), man(human)--men(soldier, employee)\}. When students' understanding of the meaning of words deviates, it also affects their correct use of noun singular plurals.

Further analysis shows that the causes of these two nouns singular and plural misuse types are mainly reflected in three aspects: the difference between Chinese and English characters, the difference between Chinese and English language types, the difference of Chinese and English cultural thinking. These differences are the embodiment of the influence of negative language transfer on English writing. In order to overcome or eliminate the effect of negative language transfer on the use of nouns acquired in English, we should start with guiding students to the essential rules of the two languages and cultural thinking, and improve the students' overall language level and ability.

\subsection{Errors in the Complementizer of Clause}

English is a morphological language that focuses on explicit connections. English has clear logical 
relationships and obvious signs between main and subordinate clauses. Chinese is an intentional language with no obvious connectives. There is an invisible connection between sentences that expresses logical relationships in terms of meaning. Chinese focuses on internal logic rather than on the function of sentence constituents. The different features of the two languages between main and subordinate sentences determine the conditions under which the language transition occurs. English usually uses articulation to express specific logical and syntactic relationships in the construction of words and sentences. Chinese mainly uses correlation and consistency in meaning to achieve contextual connection [28]. Therefore, in high school students' English writing, students often neglect the use of conjunctions and the difficulty in mastering English compound sentences, making their English writing illogical.

For example, the following clause errors were found in the collected essays.

i) I am thinking about you all the time, I am suffering from my irresponsibility, and my recreance. (False)

j) I am thinking about you all the time, and I am suffering from my irresponsibility and my recreance. (True)

This example represents the most common mistake made by Chinese high school students. There are no connecting words between sentences. This is because Chinese sentences are flexible in structure and loosely arranged, with one sentence following another like running water, and the end of the sentence is the boundary. English, on the other hand, strictly stipulates that no comma can be used between independent sentences without a conjunction, otherwise it is regarded as a sick sentence [29].

\section{CONCLUSION}

The interference of negative language transfer on English learning and English writing of Chinese high school students exists objectively. This paper illustrates this point by collecting 80 high school students English compositions and analyzing the grammatical errors in their writings. Based on the analysis of the grammar of the material, there are five main categories of errors: determiner $(9,9 \%)$, tense $(29,30 \%)$, subject-predicate agreement $(16,17 \%)$, the plural form of Noun $(32,33 \%)$, the complementizer of Clause $(11,11 \%)$

These errors, which are related to syntax and morpheme in English and Chinese, are affected by the negative transfer of Chinese mother tongue. Therefore, due to the similarities and differences between the mother tongue and the second language, negative transfer is inevitable in the process of English learning.
From the point of view for guiding second language learners to learn second language better, it is necessary to actively study and explore scientific second language teaching methods. Guide students to correctly realize the transfer error, help students carefully analyze the causes of the error. Hence, students in the learning process consciously avoid the impact of mother tongue negative transfer.

In addition, the current research on the characteristics of English writing in the context of mother tongue negative transfer, the factors affecting English writing and the differences in process are less discussed. Second language researchers should actively pay more attention to the impact of mother tongue negative transfer on English writing, and carry out a further exploration.

In general, English teachers and learners should actively use positive transfer in English teaching and learning process. For English writing, it is necessary to effectively avoid negative transfer, and put forward targeted effective measures to promote and improve learners' knowledge of English language. These results offer a guideline for second language learners on how to overcome the negative transfer in the process of second language acquisition.

\section{REFERENCES}

[1] Li, Li-Sheng, The globalization of English and linguistic diversity. Journal of Yunnan Normal University, 2005, Vol.37 No.1: 109-112.

[2] Jao, Bin-kai, English globalization and its nativization in China. Journal of Xuchan University, 2009, Vol.28 No.1:89-91.

[3] Chen,Hong-Zhen, A Brief Analysis of the Negative Transfer of Mother Tongue in English Learning. Overseas English, 2010, 324-325+340.

[4] Yang, Ying-Mei, Negative language transfer and second language acquisition. Science \& Technology Information, 2006, 326.

[5] Yi,Jin-Lan, The Negative and Positive Effects of Negative Language Transfer on SLA. Journal of Hubei Agricultural College, 2003, Vol.23 No.4: 7982.

[6] Tang, Yu, Analysis on the Phenomenon of Negative Language Transfer in English Learning. ShaanXi Youth, 2017, 108.

[7] Yang,Jing, How to avoid the negative transfer of mother tongue in foreign language learning. Higher Education in Building Material Science, 2001, Vol.20 No.6: 101-102. 
[8] Li,Si-qi,,On the Influence of Negative Transfer of Mother Tongue in English Learning. English Square, 2017, 106-107.

[9] J.C. and Renandya,Richards, Methodology in Language Teaching: An Anthology of Current Practice. Cambridge.Cambridge University Press. 2002, pp 303.

[10] C.R.McDonald, and McDonald,Teaching Writing. Landmark and Horizons. Illinois: Southern Illinois University Press. 2002, pp 47.

[11] Weigle, S.C. Assessing Writing. Cambridge: Cambridge University Press. 2002, pp 15.

[12] Gao,Xiang, A cognitive analysis of language input theory, Foreign and Foreign Teaching, 2005, 6.1517.

[13] Chen Liping, Analysis of the current situation and countermeasures of high school English writing teaching, Journal of Kaifeng College of Education, 2016, 36. 246-247.

[14] Wei Qian, A study of negative migration of vocabulary native language in English writing, Heilongjiang Science, 2016, 151. 21-25.

[15] Li Jinghui, An investigation and research on the problems in junior high school English writing[D], Northeast Normal University, Changchun, 2008.

[16] R., Wei, \& J. Su, The statistics of English in China, An analysis of the best available data from government sources. English Today, 2012, 28(3), $10-14$.

[17] Zhang Qian. A study on the countermeasures of negative transfer of Chinese thinking to students' English writing. Gao Kao (17), 2021, 97-98.

[18] Li Juan. A multidimensional exploration of high school English writing teaching. Famous Teachers Online (17), 2021, 37-38.

[19] T. Y. Wang, Ten-year review and prospect of study abroad education in China. Journal of Hebei Normal University (Education Science Edition) (04), 2021, 73-80.

[20] N, Snape, Representational Deficits in SLA: Studies in Honor of Roger Hawkins. John Benjamins Publishing Company., Amsterdam. 2019, pp 27.

[21] C, Lyons, Definiteness. Cambridge University Press: Cambridge. 1999, pp 171-172

[22 K, Bardovi-Harlig, Tense and aspect in second language acquisition: form, meaning, and use. Language Learning, 2000, 50(1), X-461.
[23] Chen, Juan. Research on the influence of negative native language transfer on the syntax of junior high school English writing and countermeasures (Master's thesis, Southwest University), 2002.

[24] Xie Feifei. The influence of Chinese migration phenomenon on junior high school students' English writing (Master's thesis, Guizhou Normal University), 2020.

[25] Wu Aixiang, Negative migration of Chinese to English writing and coping strategies, Jiangxi Education, 2019, 10: 21-24

[26] Zhang, Huan, The plural expressions of nouns in modern Chinese and their marking problems.Nanchan University, 2010.

[27] Zhang, Xue-Li, Chinese and English language comparison and translation. MING, 2017, No20: 362.

[28] He, Hengheng, On the phenomenon of negative syntactic transfer in English writing, English Abroad, 2015, 209-210

[29] Deng Yuyan, Insights of negative native language migration on English grammar teaching - an analysis of syntactic errors based on college students' English writing, Journal of Jiamusi Vocational College 9, 2016, 332-333. 